\title{
Clinicopathological heterogeneity between primary and metastatic sites of gastroenteropancreatic neuroendocrine neoplasm
}

\author{
Huiying Shi ${ }^{1+}$, Chen Jiang ${ }^{1+}$, Qin Zhang ${ }^{2}$, Cuihua $\mathrm{Qi}^{1}$, Hailing Yao ${ }^{1}$ and Rong Lin ${ }^{1 *}$
}

\begin{abstract}
Background: Chromogranin A (CgA), synaptophysin (Syn) and the Ki-67 index play significant roles in diagnosis or the evaluation of the proliferative activity of gastroenteropancreatic neuroendocrine neoplasms (GEP-NENs). However, little is known about whether these biological markers change during tumor metastasis and whether such changes have effect on prognosis.

Methods: We analyzed 35 specimens of both primary and metastatic tumor from 779 patients who had been diagnosed as GEP-NENs at Wuhan Union Hospital from August 2011 to October 2019. The heterogeneity of CgA, Syn and Ki-67 index was evaluated by immunohistochemical analysis.

Results: Among these 779 patients, the three most common sites of NENs in the digestive tract were the pancreas, rectum and stomach. Metastases were found in 311 (39.9\%) patients. Among the 35 patients with both primary and metastatic pathological specimens, differences in the Ki-67 level were detected in 54.3\% of the patients, while $37.1 \%$ showed a difference in CgA and only $11.4 \%$ showed a difference in Syn. Importantly, due to the difference in the Ki-67 index between primary and metastatic lesions, the WHO grade was changed in $8.6 \%$ of the patients. In addition, a Kaplan-Meier survival analysis showed that patients with Ki-67 index variation had a shorter overall survival $(p=0.0346)$, while neither Syn variation nor CgA variation was related to patient survival $(p=0.7194, p=$ 0.4829).

Conclusions: Our data indicate that primary and metastatic sites of GEP-NENs may exhibit pathological heterogeneity. Ki-67 index variation is closely related to the poor prognosis of patients with tumor metastasis, but neither Syn variation nor CgA variation is related to patient prognosis. Therefore, clinicopathologic evaluation of the primary tumor and metastatic sites could be helpful for predicting the prognosis.
\end{abstract}

Keywords: Gastroenteropancreatic neuroendocrine neoplasms (GEP-NENs), Chromogranin (CgA), Synaptophysin (Syn), Ki-67 index, Metastasis, Heterogeneity

\footnotetext{
* Correspondence: selinalin35@hotmail.com

${ }^{\dagger}$ Huiying Shi and Chen Jiang contributed equally to this work.

'Department of Gastroenterology, Union Hospital, Tongji Medical College,

Huazhong University of Science and Technology, Wuhan 430022, China

Full list of author information is available at the end of the article
}

C C The Author(s). 2020 Open Access This article is licensed under a Creative Commons Attribution 4.0 International License, which permits use, sharing, adaptation, distribution and reproduction in any medium or format, as long as you give appropriate credit to the original author(s) and the source, provide a link to the Creative Commons licence, and indicate if changes were made. The images or other third party material in this article are included in the article's Creative Commons licence, unless indicated otherwise in a credit line to the material. If material is not included in the article's Creative Commons licence and your intended use is not permitted by statutory regulation or exceeds the permitted use, you will need to obtain permission directly from the copyright holder. To view a copy of this licence, visit http://creativecommons.org/licenses/by/4.0/ The Creative Commons Public Domain Dedication waiver (http://creativecommons.org/publicdomain/zero/1.0/) applies to the data made available in this article, unless otherwise stated in a credit line to the data. 


\section{Introduction}

Neuroendocrine neoplasms (NENs) are a group of rare and highly heterogeneous neoplasms originating from peptidergic neurons and neuroendocrine cells, which can exist in all parts of the body [1]. Recently, the incidence of NENs has been on the rise. The actual incidence rate increased 6.4-fold from 1973 (1.09 per 100, 000) to 2012 (6.98 per 100,000) according to data from the National Cancer Institute's Surveillance, Epidemiology, and End Results (SEER) Program [2]. Gastroenteropancreatic neuroendocrine neoplasms (GEP-NENs) are reportedly the most common of these, and account for about $66 \%$ of all NENs [3]. In addition, 21 to $73.4 \%$ of GEP-NENs were found to have metastases at the time of diagnosis [4-6].

Chromogranin A (CgA) and synaptophysin (Syn) widely exist in neuroendocrine cells, and are currently necessary markers for the diagnosis of NENs [7, 8]. CgA was initially found in chromaffin particles of adrenal medulla containing catecholamines [9]. It is a kind of acidic hydrophilic secreted protein found in the secretory vesicles of neuroendocrine cells [10]. Syn is an integral membrane glycoprotein present in presynaptic neuron vesicles and the vesicles of normal and neuroendocrine tumor cells $[7,11]$. In addition, the Ki-67 index plays a crucial role in the World Health Organization (WHO) grading system for GEP-NENs: (grade 1) G1 tumors have a Ki-67 index <3\%; (grade 2) G2 tumors have an index of 3-20\%; and (grade 3) G3 tumors have an index $>20 \%$ [12]. Syn, CgA and the Ki-67 index play important roles in the diagnosis of NENs. However, little is known about whether these compounds change during tumor metastasis and whether such changes play a role in the overall process of metastasis.

Therefore, the purposes of this study were to investigate the clinicopathological heterogeneity of CgA, Syn, and the Ki-67 index between the primary and metastatic sites, and to evaluate the influence of these clinicopathological features on the prognosis in patients with metastatic GEP-NENs.

\section{Materials and methods}

\section{Patients and data collection}

This study retrospectively collected and analyzed data from 779 patients diagnosed with GEP-NENs at Wuhan Union Hospital from 2011 to 2019; specimens of both primary and metastatic sites were available for 35 patients. The diagnosis of NENs mainly depended on the histological morphology as well as the immunohistochemical staining results of various neuroendocrine markers like CgA and Syn. NENs could also be diagnosed by CD56 or neuron-specific enolase when the immunostaining result of CgA or Syn was absent [13]. All specimens were obtained by surgical excision, fine needle aspiration, and/or core biopsy. Patients for whom complete clinical data were not available for extraction were excluded. The following demographic and clinical characteristics of the patients were collected: age, sex, primary and metastatic tumor sites, immunohistochemical results (CgA, Syn and Ki-67 index), and survival time. The grading system used in this study was based on the WHO 5th edition classification (2019) of digestive system tumors, in which NENs are classified as welldifferentiated neuroendocrine tumors (NETs), poorly differentiated neuroendocrine carcinomas (NECs), and mixed neuroendocrine-non-neuroendocrine neoplasm (MiNEN). NETs were further divided into three grades based on the Ki-67-positive index: G1: <3\%, G2: 3-20\%, G3: > 20\% [12]. According to the AJCC cancer staging manual, if the metastasis occurred simultaneously with the primary tumor or within 4 months after the initial resection of the primary tumor, the metastasis was considered to be synchronous; if the metastasis occurred more than 4 months after the initial resection of the primary tumor, it was considered as metachronous [14].

The study was approved by the Ethics Committee of Tongji Medical College, Huazhong University of Science and Technology (IORG number: IORG0003571) and was conducted in accordance with the Declaration of Helsinki.

\section{Immunohistochemistry}

We performed immunohistochemical staining for CgA, Syn and Ki-67. The primary and metastatic tumor tissues were fixed in $4 \%$ paraformaldehyde and embedded in paraffin blocks. Each block was cut into $4 \mu \mathrm{m}$-thick section, and deparaffinized with xylene and rehydrated with ethanol. Then the sections were incubated with hydrogen peroxide at the room temperature, then antigen retrieval and serum blocking were performed. After these steps, they were incubated with the CgA (M0869, Dako, Glostrup, Denmark), Syn (M7315, Dako) and Ki67 antibodies (MIB-1, DAKO, Agilent Technologies, Santa Clara, CA, USA) at $37^{\circ} \mathrm{Cfor} 1 \mathrm{~h}$. Then they were incubated with the secondary antibody containing the biotin. Last, slides were visualized by using the DAB (AR1022, BOSTER Biological Technology), stained with hematoxylin, dehydrated with ethanol, transparentized with xylene, and counted.

The staining results for CgA and Syn were graded according to the extent of positive cells as follows: grade I (negative, less than $5 \%$ positive tumor cells), grade II (focally positive, 5 to $50 \%$ positive tumor cells), grade III (positive, more than 50\% positive tumor cells) [15]. For Ki-67 staining, the areas with abundant and more positive tumor cells were selected. The Ki-67 labeling index was determined by calculating the percentage of positive nuclei of 2000 tumor cells in the densest area of each 
slide [16]. Each slide was reexamined by the pathologist (Q.Z.).

\section{Statistical analysis}

SPSS software v24.0 (IBM, Armonk, NY, USA) or GraphPad Prism v6.0c (GraphPad Software, San Diego, CA, USA) was used for statistical calculation and data processing. The clinicopathological characteristics of patients were expressed as median and range, absolute value or fractions. Overall survival (OS) was defined as the date of initial diagnosis to the last follow-up or date of death. Survival curves were drawn according to the Kaplan-Meier analysis, and differences between groups were assessed using the log-rank test. $P<0.05$ was regarded as statistically significant.

\section{Results}

Patient clinical and pathological characteristics

A total of 779 patients with GEP-NENs were included in the analysis; their clinicopathological characteristics were shown in Table 1. There were 460 (59.1\%) males and 319 (40.9\%) females (male-female ratio of 1.44 ). The median age at diagnosis was 55 y (range: $13-87$ y). Among these 779 patients, the three most common sites of NENs in the digestive tract were the pancreas, rectum and stomach. Pathological diagnosis showed that, among the 779 patients, NET-G1 accounted for $40.2 \%$, NET-G2 18.5\%, NET-G3 0.5\%, NEC 34.7\% and MiNEN 5.1\%. Metastasis occurred in $39.9 \%$ of the patients $(311 / 779)$. The positive rates of immunohistochemical staining for $\mathrm{CgA}$ and Syn were 57.5 and $85.4 \%$, respectively, and the double-positive rate was $56.6 \%(441 / 779)$. For 35 patients with metastatic specimens, 25 (71.4\%) had metastatic tumors simultaneously, and 10 (28.6\%) had metachronous metastases.

\section{Heterogeneity of $\mathrm{CgA}$, Syn and the Ki-67 index between} primary and metastatic sites

For 35 patients with both primary and metastatic specimens, the clinicopathological differences between the primary and metastatic sites were analyzed. There was no significant difference in the overall positive rates of $\mathrm{CgA}$ and Syn, or in the grading or classification of tumors between the primary and metastatic sites (Supplementary Table 1). However, the variation of CgA, Syn and the Ki-67 index existed between the primary and metastatic sites. Examples of CgA, Syn and the Ki-67 index variation between the primary tumor sites and metastatic sites were shown in Fig. 1.

\section{$\mathrm{CgA}$}

Of the 35 patients, while 18 (51.4\%) had no difference in CgA between the primary and metastatic sites, 13 (37.1\%) showed a variation in CgA (Table 2). The CgA
Table 1 Clinical characteristics in 779 patients with GEP-NENs

\begin{tabular}{|c|c|}
\hline Variables & Total $n=779(\%)$ \\
\hline Age at diagnosis (years) & $55(13-87)$ \\
\hline \multicolumn{2}{|l|}{ Sex } \\
\hline Male & $460(59.1)$ \\
\hline Female & $319(40.9)$ \\
\hline \multicolumn{2}{|l|}{ Primary tumor site } \\
\hline Pancreas & $216(27.7)$ \\
\hline Rectum & $208(26.7)$ \\
\hline Stomach & $144(18.5)$ \\
\hline Esophagus & $44(5.6)$ \\
\hline Duodenum & $31(4.0)$ \\
\hline Colon & $29(3.7)$ \\
\hline Gallbladder & $18(2.3)$ \\
\hline Appendix & $11(1.4)$ \\
\hline Small intestine & $4(0.5)$ \\
\hline Other sites & $74(9.5)$ \\
\hline \multicolumn{2}{|l|}{ Tumor grade and type } \\
\hline NET G1 & $313(40.2)$ \\
\hline NET G2 & $144(18.5)$ \\
\hline NET G3 & $4(0.5)$ \\
\hline NEC & $270(34.7)$ \\
\hline MINEN & $40(5.1)$ \\
\hline Unknown & $8(1.0)$ \\
\hline \multicolumn{2}{|l|}{${ }^{\mathrm{C}} \mathrm{CgA}$} \\
\hline Positive & $448(57.5)$ \\
\hline Negative & $221(28.4)$ \\
\hline Unknown & $110(14.1)$ \\
\hline \multicolumn{2}{|l|}{${ }^{a}$ Syn } \\
\hline Positive & $665(85.4)$ \\
\hline Negative & $15(1.9)$ \\
\hline Unknown & $99(12.7)$ \\
\hline Metastasis & 311 (39.9) \\
\hline
\end{tabular}

Abbreviations: GEP-NENs gastroenteropancreatic neuroendocrine neoplasms, NET neuroendocrine tumors, NEC neuroendocrine carcinoma, MiNEN mixed neuroendocrine-non-neuroendocrine neoplasm, CgA chromogranin; Syn, synaptophysin. ${ }^{\text {a }}$ The expression of CgA or Syn in primary site

variation rate was $42.9 \%$ (3/7) for rectal NENs, $42.9 \%$ (6/ 14) for pancreatic NENs, and $50 \%$ (3/6) for gastric NENs (Fig. 2a). The CgA variation rate was $33.3 \%(2 / 6)$ for NET-G1, 42.9\% (3/7) for NET-G2, 0\% for NET-G3, and $40 \%(8 / 20)$ for NEC (Fig. 2b). The CgA variation rate was $16 \%(4 / 25)$ for synchronous metastases and $90 \%(9 /$ 10) for metachronous metastases (Fig. 2c).

Syn

With regard to Syn variation between the primary and metastatic sites, while 31/35 (88.6\%) patients had no change, $4 / 35$ (11.4\%) patients had variation (Table 2). 


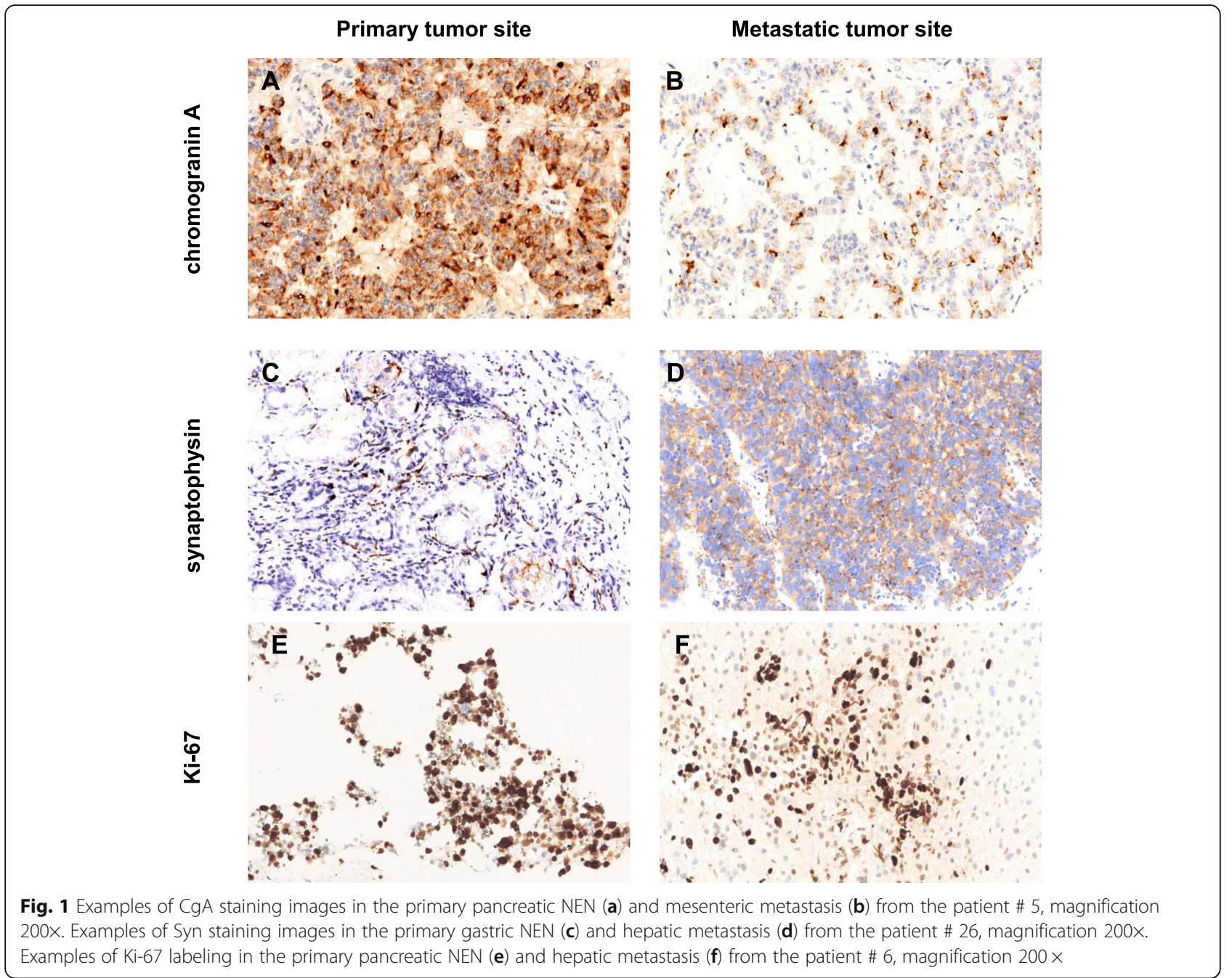

The Syn variation rate was $28.6 \%(2 / 7)$ for rectal NENs, $7.1 \%$ (1/14) for pancreatic NENs, and $16.7 \%$ (1/6) for gastric NENs (Fig. 3a). With regard to the WHO classification, Syn variation was observed in 20\% (4/20) of NEC, but not in NET-G1, NET-G2, or NET-G3 (Fig. 3b). The Syn variation rate was $12 \%(3 / 25)$ for synchronous metastases and $10 \%$ (1/10) for metachronous metastases (Fig. 3c).

\section{Ki-67 index}

Our results showed that the mean number and standard deviation of Ki-67-positive cells in primary tumor was $37.89 \pm 33.04(\%)$ and the metastatic lesion was $39 \pm$ 27.48 (\%). Ki-67 index variation was observed in 19 patients (54.3\%); 8 (42.1\%) showed up-regulation (from primary to metastasis) and 11 (57.9\%) showed downregulation. In 16 of these 35 patients (45.7\%), despite this difference in Ki-67 index between primary and metastatic sites, there was no difference in classification. Notably, for $3 / 35$ patients (8.6\%), the classification changed: 1 patient increased from NET-G1 to NET-G2, 1 increased from NET-G1 to NET-G3, and 1 decreased from NET-G2 to NET-G1 (Table 2). The Ki-67 index variation was seen in $85.7 \%(6 / 7)$ of rectal NENs, $50 \%$ (3/6) of gastric NENs, and 35.7\% (5/14) of pancreatic NENs (Fig. 4a). Moreover, Ki-67 index variation was as high as $60 \%(12 / 20)$ in NEC, $50 \%(3 / 6)$ in NET-G1, $42.9 \%(3 / 7)$ in NET-G2, and $100 \%$ in NET-G3 (Fig. $4 \mathrm{~b}$ ). The Ki-67 index variation was observed in $44 \%(11 / 25)$ of synchronous metastases and $80 \%(8 / 10)$ of metachronous metastases (Fig. 4c).

\section{Survival analysis}

The Kaplan-Meier survival analysis included sex, CgA variation, Syn variation, Ki-67 index variation, primary tumor site and metastatic tumor site and treatment methods. The results showed that the Ki-67 index variation group had a poorer prognosis than patients in the Ki-67 index non-variation group [hazard ratio 6.800, $95 \%$ confidence interval 1.833-25.230; $p=0.0346]$. For Ki-67 variation group, there was no significant difference 
Table 2 CgA, Syn and Ki-67 index variation between primary and metastatic sites

\begin{tabular}{|c|c|c|c|c|c|c|c|c|c|c|}
\hline \multirow{2}{*}{$\begin{array}{l}\text { Patient } \\
\#\end{array}$} & \multirow{2}{*}{$\begin{array}{l}\text { Primary } \\
\text { tumor } \\
\text { site } \\
\text { Site1\# }\end{array}$} & \multirow{2}{*}{$\begin{array}{l}\text { Metastatic } \\
\text { tumor site } \\
\text { Site2\# }\end{array}$} & \multicolumn{2}{|c|}{${ }^{\mathrm{a}} \mathrm{CgA}$ variability } & \multicolumn{2}{|c|}{ a Syn variability } & \multicolumn{2}{|c|}{ Ki-67 index(\%) } & \multirow{2}{*}{$\begin{array}{l}\text { Survival } \\
\text { time }\end{array}$} & \multirow{2}{*}{$\begin{array}{l}\text { WHO class } \\
\text { changes }\end{array}$} \\
\hline & & & \multicolumn{2}{|c|}{ Site1\# Site2\# } & \multicolumn{2}{|c|}{ Site1\# Site2\# } & \multicolumn{2}{|c|}{ Site1\# Site2\# } & & \\
\hline 1 & pancreas & liver & III & III & III & III & 1 & 1 & 57 & - \\
\hline 2 & pancreas & liver & III & III & III & III & 10 & 10 & 75 & - \\
\hline 3 & pancreas & abdominal wall & । & $\|$ & $\|$ & । & 40 & 80 & 83 & $\mathrm{NEC} \rightarrow \mathrm{NEC}$ \\
\hline 4 & pancreas & liver & III & III & III & III & 2 & / & 23 & - \\
\hline 5 & pancreas & mesentery & III & $\|$ & III & III & 10 & 5 & 12 & NET G2 $\rightarrow$ NET G2 \\
\hline 6 & pancreas & liver & $\|$ & III & III & III & 80 & 60 & 3 & $\mathrm{NEC} \rightarrow \mathrm{NEC}$ \\
\hline 7 & pancreas & liver & I & I & $\|$ & $\|$ & 30 & 25 & 4 & NET G3 $\rightarrow$ NET G3 \\
\hline 8 & pancreas & liver & III & $\|$ & III & III & 2 & 2 & 1 & - \\
\hline 9 & pancreas & liver & III & III & III & III & 10 & 10 & 7 & - \\
\hline 10 & pancreas & liver & III & III & III & III & 40 & 40 & 0 & - \\
\hline 11 & pancreas & liver & III & / & III & III & 5 & / & 3 & - \\
\hline 12 & pancreas & lymph node & / & / & III & III & 30 & 30 & 19 & - \\
\hline 13 & pancreas & liver & I & $\|$ & III & III & 15 & 15 & 27 & - \\
\hline 14 & pancreas & pelvic cavity & I & $\|$ & III & III & 10 & 5 & 70 & $\mathrm{NET}$ G2 $\rightarrow$ NET G2 \\
\hline 15 & rectum & liver & / & / & III & III & 10 & 10 & 97 & - \\
\hline 16 & rectum & liver & III & III & III & III & 2 & 5 & 27 & NET G1 $\rightarrow$ NET G2 \\
\hline 17 & rectum & liver & $\|$ & I & III & III & 2 & 25 & 3 & NET G1 $\rightarrow$ NET G3 \\
\hline 18 & rectum & lymph node & III & I & III & III & 60 & 80 & 48 & $\mathrm{NEC} \rightarrow \mathrm{NEC}$ \\
\hline 19 & rectum & lymph node & III & $\|$ & III & III & 60 & 80 & 12 & $\mathrm{NEC} \rightarrow \mathrm{NEC}$ \\
\hline 20 & rectum & Liver & I & I & I & III & 95 & 90 & 20 & $\mathrm{NEC} \rightarrow \mathrm{NEC}$ \\
\hline 21 & rectum & lymph node & 1 & I & I & III & 95 & 90 & 20 & $\mathrm{NEC} \rightarrow \mathrm{NEC}$ \\
\hline 22 & stomach & liver & I & I & III & III & 70 & 70 & 8 & - \\
\hline 23 & stomach & iliac fossa & III & $\|$ & III & III & 35 & 30 & 16 & $\mathrm{NEC} \rightarrow \mathrm{NEC}$ \\
\hline 24 & stomach & lymph node & I & I & III & III & / & 80 & 15 & - \\
\hline 25 & stomach & lung & 1 & $\|$ & III & III & 70 & 70 & 15 & - \\
\hline 26 & stomach & liver & I & 1 & $\|$ & III & 80 & 50 & 1 & $\mathrm{NEC} \rightarrow \mathrm{NEC}$ \\
\hline 27 & stomach & liver & III & $\|$ & III & III & 80 & 50 & 36 & $\mathrm{NEC} \rightarrow \mathrm{NEC}$ \\
\hline 28 & duodenum & liver & III & III & III & III & 5 & 2 & 5 & NET G2 $\rightarrow$ NET G1 \\
\hline 29 & duodenum & liver & $\|$ & $\|$ & III & III & 5 & 5 & 11 & - \\
\hline 30 & duodenum & adrenal gland & $\|$ & $\|$ & III & III & 20 & 35 & 29 & $\mathrm{NEC} \rightarrow \mathrm{NEC}$ \\
\hline 31 & colon & mesentery & $\|$ & $\|$ & III & III & 60 & / & 55 & - \\
\hline 32 & unknown & liver & / & / & III & III & 80 & 60 & 5 & $\mathrm{NEC} \rightarrow \mathrm{NEC}$ \\
\hline 33 & unknown & liver & $\|$ & III & III & III & 80 & 90 & 1 & $\mathrm{NEC} \rightarrow \mathrm{NEC}$ \\
\hline 34 & unknown & peritoneal & $\|$ & $\|$ & $\|$ & $\|$ & 30 & 30 & 21 & - \\
\hline 35 & unknown & rectum & III & III & III & III & 1 & 2 & 61 & NET G1 $\rightarrow$ NET G1 \\
\hline
\end{tabular}

Abbreviations: CgA chromogranin, Syn synaptophysin, $N E C$ neuroendocrine carcinoma; ${ }^{a} \mathrm{CgA}$ and Syn graded according to the percent of positive cells as follows: I: $<5 \%$, II: $5-50 \%$, and III: > 50\%

in survival time between NET and NEC groups, between synchronous and metachronous metastatic tumor groups, between Ki-67 index up-regulated and down-regulated groups (Fig. 5g-i). To explore the different treatment methods on patient survival, patients were grouped into four groups including surgery, adjuvant therapy, surgery and adjuvant therapy, and no treatment. The results showed that the prognosis of patients receiving surgery or both surgery and adjuvant therapy was better than that of patients who received adjuvant therapy only $(p=0.0350, p=$ 0.0109) (Fig. 6). 

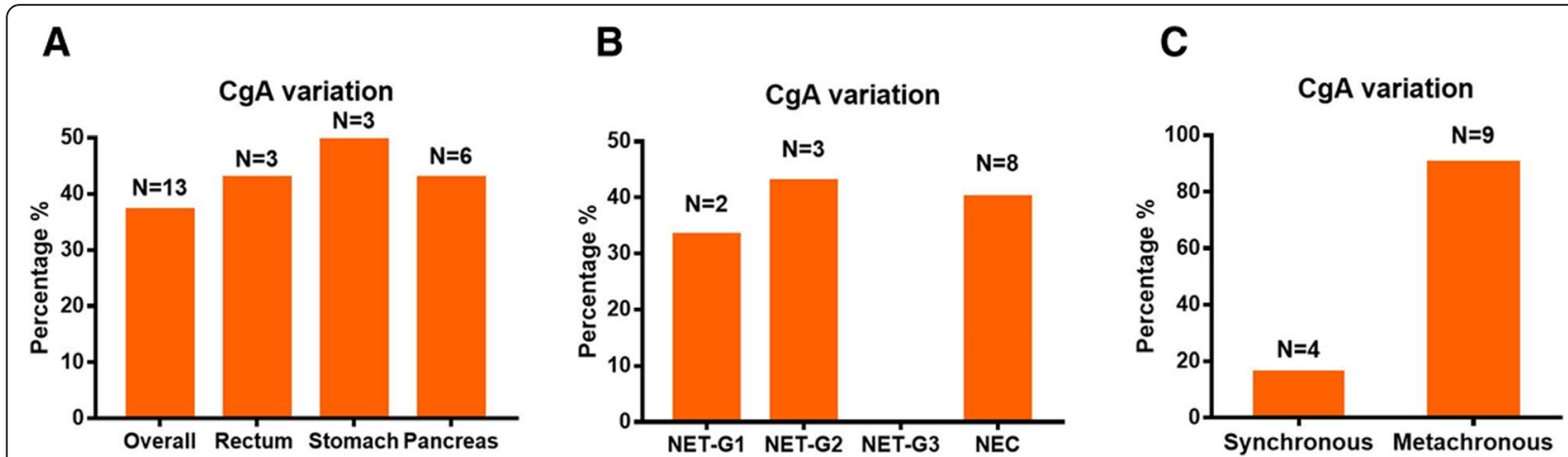

Fig. 2 Percentages of patients with CgA-variation at different primary tumor sites (a). Percentages of patients with CgA-variation under different classifications of NENs (b). Percentages of patients with CgA-variation under different types of metastatic tumors (c)

\section{Discussion}

GEP-NENs represent a heterogeneous family of neoplasms with variable biological and clinical characteristics. Few studies have attempted to assess the heterogeneity of the expression of biological markers in primary and metastatic GEP-NENs. Therefore, in this study, we investigated the pathological heterogeneity of primary and metastatic sites of GEP-NENs and the effect of such heterogeneity of pathological indicators on the prognosis of patients.

In the SEER database, the rectum and small intestine are the most common sites of GEP-NENs [2, 3]. Our results showed that the pancreas, rectum and stomach were the most common sites, which were consistent with the results of a large retrospective single-center study in China [17]. We found that the metastasis rate of patients with GEP-NENs was 39.9\%, and the most common site of distant metastasis was the liver. It has been reported that distant metastasis of NENs is a major factor affecting the prognosis [18].

NENs synthesize, store and secrete various peptides and amines [19], which exist in the blood or tissues of patients. These have become important markers for the diagnosis and follow-up of patients with NENs [20]. Among them, CgA and Syn are considered to be the most important biomarkers for the diagnosis of NENs $[21,22]$. Our results showed that the positive rates of CgA and Syn in the primary site were 57.5 and $85.4 \%$, respectively. Many studies have shown that the CgA level and Ki-67 index are closely related to NENs metastasis [23-26], and are useful for determining the prognosis [27-30].

Although most studies have explored the relationship between these biological indicators and tumor metastasis and prognosis, little attention has been paid to the heterogeneity of marker expression between primary and metastatic tumor sites, and the impact of such heterogeneity on disease progression has not been fully evaluated. Lindholm et al. [31] found that in small-intestinal NENs, 38.5\% showed the grade variation in CgA and $54 \%$ showed the grade variation in Syn between the primary and metastatic sites. In this study, $37.1 \%$ of cases showed the variation in CgA and $11.4 \%$ showed the variation in Syn between the primary and metastatic tumor sites. The variation of CgA was in line with Lindholm's study, and we found that the variation of $\mathrm{CgA}$ in
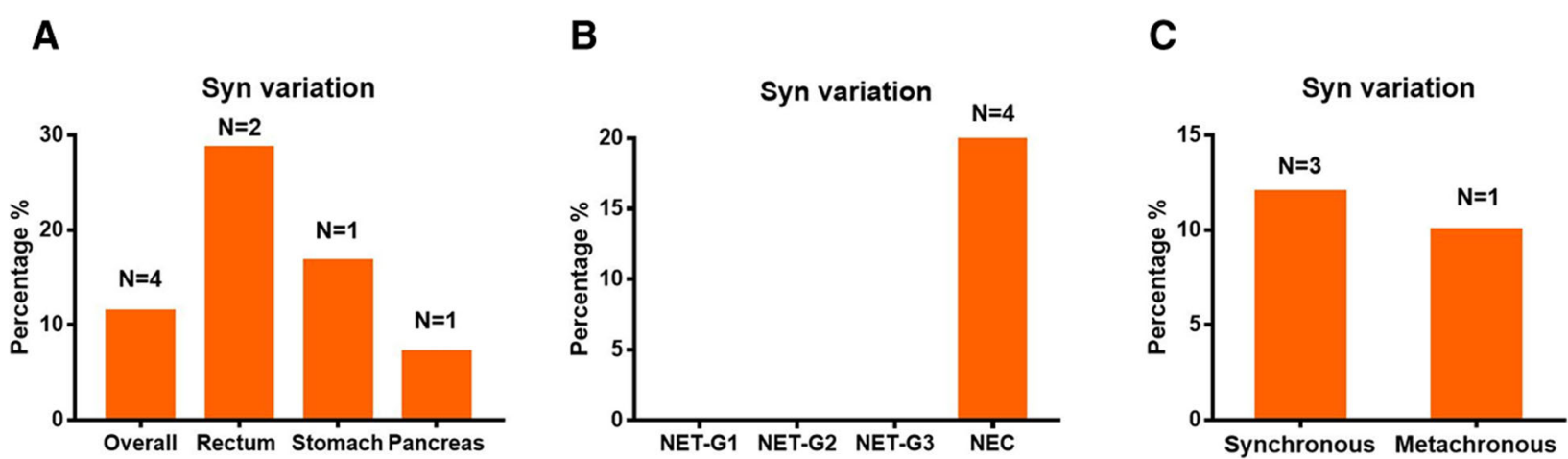

Fig. 3 Percentages of patients with Syn-variation at different primary tumor sites (a). Percentages of patients with Syn-variation under different classifications of NENs (b). Percentages of patients with Syn-variation under different types of metastatic tumors (c) 


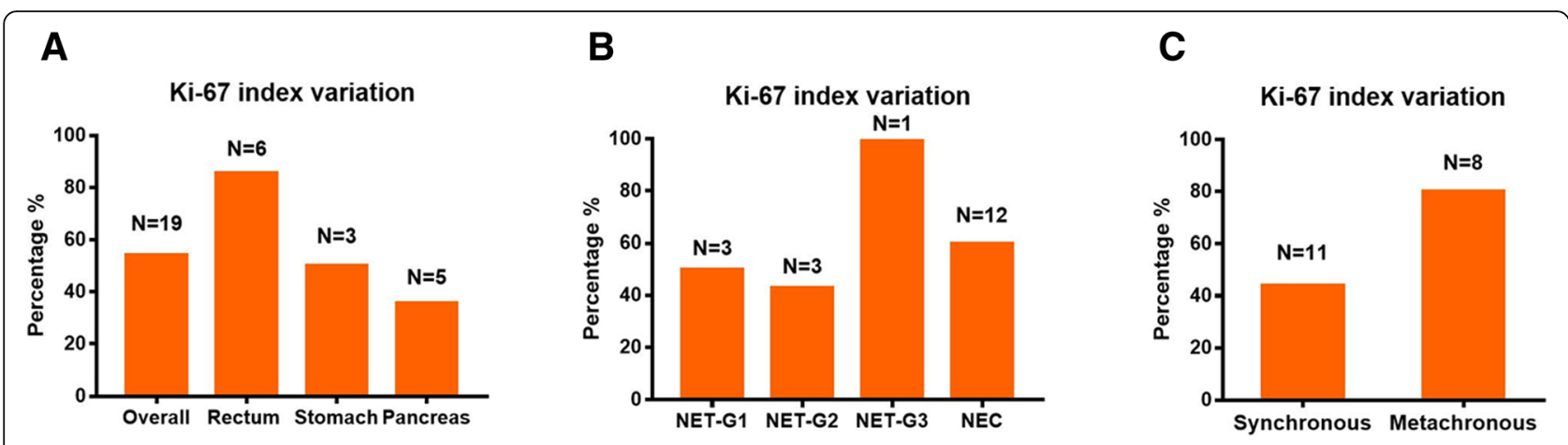

Fig. 4 Percentages of patients with Ki-67 index-variation at different primary tumor sites (a). Percentages of patients with Ki-67 index-variation under different classifications of NENs (b). Percentages of patients with Ki-67 index-variation under different types of metastatic tumors (c)

different primary tumor sites was similar, ranging from 42.9 to $50 \%$. We consider the difference may be due to the heterogeneity of NENs at different sites in Syn variation. In our study, the variation rates of Syn were different in different sites of NENs, with the highest variation rate of Syn in rectal NENs (28.6\%) while the lowest variation rate of Syn (7.1\%) in pancreatic NENs. Due to the high incidence of smallintestinal NENs in Europe and America, Lindholm et al. only focused on small-intestinal NENs, while the incidence of small-intestinal NENs in China was extremely low, so our study focused on NENs in the whole digestive tract. We consider this heterogeneity of Syn variation might be site-related, and further
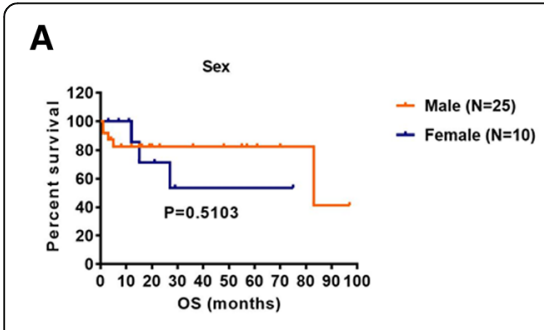

D

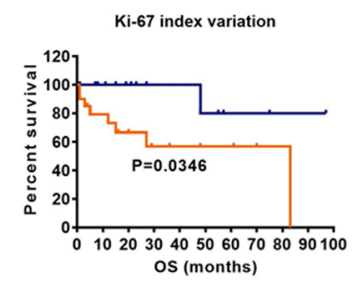

G

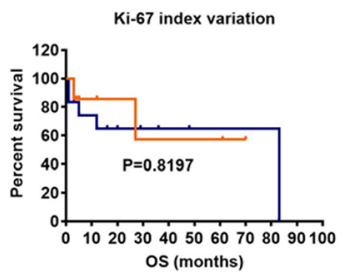

B

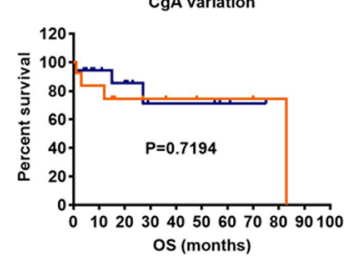

E

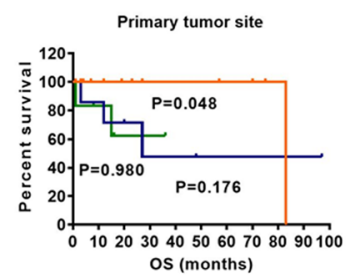

H

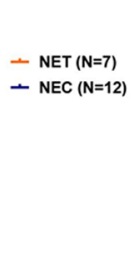

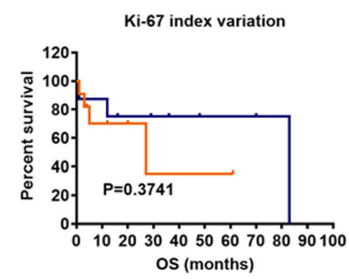

C
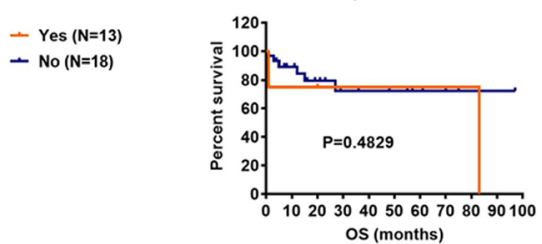

- Yes $(\mathrm{N}=4)$

- No ( $N=31)$

F
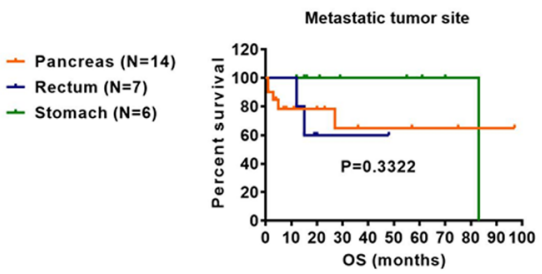

- Liver ( $\mathrm{N}=21$ ) - Lymph node $(\mathrm{N}=5)$ - Others $(\mathrm{N}=9)$

I

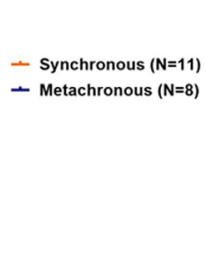

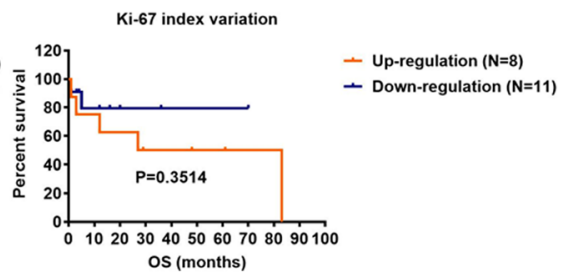

Fig. 5 Kaplan-Meier curves for overall survival in patients with multiple pathology specimens according to (a) Sex, (b) CgA variation, (c) Syn variation, (d) Ki-67 index variation, (e) Primary tumor site, (f) Metastatic tumor site. In the case of Ki-67 variation, K-M curves for overall survival in patients with multiple pathology specimens according to (g) Classification of NENs, (h) Different types of metastases, (i) Specific changes of Ki-67 index 


\section{Treatment}

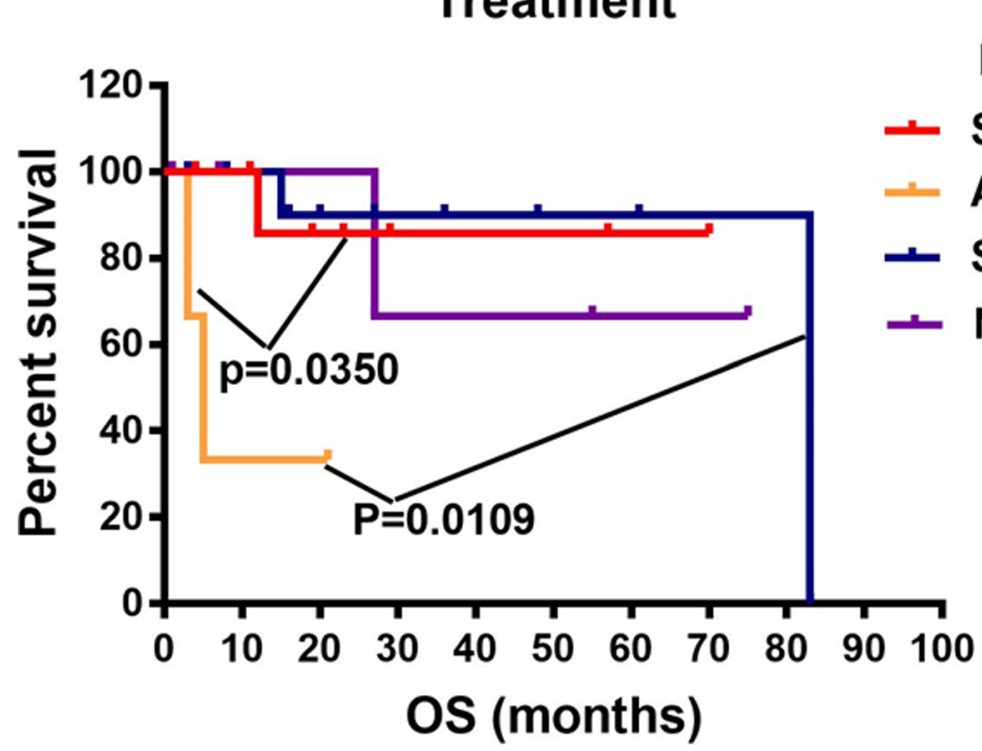

$\mathrm{p}=\mathbf{0 . 0 0 9 8}$

Surgery $(\mathrm{N}=9)$

Adjuvant therapy $(\mathrm{N}=4)$

Surgery+Adjuvant therapy $(\mathrm{N}=12)$

No Treatment $(\mathrm{N}=5)$

Surgery vs. AT $p=0.0350$

Surgery+AT vs. AT $p=0.0109$

Surgery vs. Surgery+AT $p=0.7084$

Surgery vs. No treatment $p=0.7681$

AT vs. No treatment $p=0.0701$

Surgery+AT vs. No treatment $p=0.5390$

Fig. 6 Kaplan-Meier curves for overall survival based on different treatment methods

large sample studies are needed to confirm these results.

Singh et al. [32] reported that, in $37.0 \%$ of NENs patients, the Ki-67 index changed during the course of the disease, and the WHO classification was upregulated in $27.8 \%$ of these patients. Grillo et al. found 39\% discrepancy in grade between primary and metastatic tumors [33]. Keck $\mathrm{KJ}$ et al. found grade variation occurred in $34 \%$ of patients between primary and metastatic tumors [34]. In our study, we found that, in 54.3\% of GEP-NENs patients, the Ki-67 index differed between primary and metastatic lesions; as a result, the WHO classification changed in $8.6 \%$ of the patients.

In addition, we further analyzed the heterogeneity of $\mathrm{CgA}$, Syn, and the Ki-67 index according to the primary tumor site, and found that these markers differed between the primary and metastatic sites. While there was no significant variation in CgA or Syn in the pancreas, rectum or stomach, the Ki-67 index showed obvious variation, especially in the rectum, where variation was seen in $85.7 \%$ of the patients. Interestingly, we also found that $\mathrm{CgA}$ and Ki-67 variability were more common in metachronous metastatic tumors than in synchronous metastatic tumors. The Ki-67 variation, in particular, was as high as $80 \%$ in metachronous metastases, which was in line with the study, that showed $83 \%$ of patients had an increase in Ki-67 rate in the metachronous metastatic site and a change in grade [33]. A Kaplan-Meier survival analysis showed that the overall survival time of patients with the $\mathrm{Ki}-67$ index variation was significantly shortened, which was consistent with the previous report [35], while CgA and Syn variation had no significant correlation with patient survival. The mechanism of this variation in CgA, Syn and the Ki-67 index between primary and metastatic NENs is still unclear. A previous study deduced that inconsistencies in the expression of biomarkers in primary and metastatic tumors may be caused by the heterogeneity of the tumor itself $[33,36]$, which may affect the clinical treatment [37].

In summary, this study showed that the Ki-67 index showed heterogeneity between the primary and metastatic foci, and that patients with such Ki-67 index variation had a poor prognosis. In contrast, there was little variation in CgA or Syn expression during disease progression, and CgA and Syn variation had no effect on the prognosis. The mechanism that underlies this heterogeneity has yet to be determined. Further studies with a larger sample size will be needed to specifically explore the mechanism of this tumor-marker variation.

\section{Conclusions}

Our results show that there is pathological heterogeneity between the primary and metastatic sites of GEP-NENs. The Ki-67 index shows obvious heterogeneity and patients with such $\mathrm{Ki}-67$ index variation have a poor prognosis. In contrast, there is little heterogeneity in CgA and Syn expression throughout disease progression, and their variations have no effect on the prognosis. Close attention should be given to the clinicopathological heterogeneity between the primary and metastatic lesions to better monitor the progress of NENs and potentially contribute to a more effective treatment. 


\section{Supplementary information}

Supplementary information accompanies this paper at https://doi.org/10. 1186/s13000-020-01030-x.

Additional file 1: Supplementary Table 1. CgA, Syn and grading in patients between primary and metastatic sites.

\section{Abbreviations}

CgA: chromogranin A; GEP-NENs: gastroenteropancreatic neuroendocrine neoplasms; MiNEN: mixed neuroendocrine-non-neuroendocrine neoplasm; NECs: poorly differentiated neuroendocrine carcinomas;

NENs: neuroendocrine neoplasms; NETs: well-differentiated neuroendocrine tumors; OS: Overall survival; SEER: Surveillance, Epidemiology, and End Results Program; Syn: synaptophysin; WHO: World Health Organization

\section{Acknowledgements}

The authors wish to acknowledge all participants in this study and everybody involved in the set-up and implementation of the study.

\section{Authors' contributions}

Huiying Shi and Chen Jiang contributed equally to this work. R.L. designed and supervised the study and data analysis; H.S. and C.J. performed most of data collection, analysis and wrote the manuscript; Q. Z provided pathological assessment and analysis; C.Q. and H.Y. provided help in data collection and analysis. The authors read and approved the final manuscript.

\section{Funding}

Supported by the National Natural Science Foundation of China (Nos. 81770539 and 81572428), and the National key research and development program of China (No. 2017YFC0110003). The funding body had no part in the design of the study and collection, analysis, and interpretation of data and in writing the manuscript.

\section{Availability of data and materials}

The datasets used and/or analyzed during the current study are available from the corresponding author on reasonable request.

\section{Ethics approval and consent to participate}

The study was approved by the Ethics Committee of Tongji Medical College, Huazhong University of Science and Technology (IORG number: IORG0003571).

\section{Consent for publication}

Not applicable.

\section{Competing interests}

None.

\section{Author details}

'Department of Gastroenterology, Union Hospital, Tongji Medical College, Huazhong University of Science and Technology, Wuhan 430022, China. ${ }^{2}$ Department of Pathology, Union Hospital, Tongji Medical College, Huazhong University of Science and Technology, Wuhan 430022, China.

Received: 10 May 2020 Accepted: 4 September 2020

Published online: 11 September 2020

\section{References}

1. Oberg K. Neuroendocrine tumors (NETs): historical overview and epidemiology. Tumori. 2010;96(5):797-801.

2. Dasari A, Shen C, Halperin D, Zhao B, Zhou S, Xu Y, et al. Trends in the incidence, prevalence, and survival outcomes in patients with neuroendocrine tumors in the United States. JAMA Oncol. 2017:3(10): 1335-42.

3. Modlin IM, Lye KD, Kidd M. A 5-decade analysis of 13,715 carcinoid tumors. Cancer. 2003;97(4):934-59.

4. Yao JC, Hassan M, Phan A, Dagohoy C, Leary C, Mares JE, et al. One hundred years after "carcinoid": epidemiology of and prognostic factors for neuroendocrine tumors in 35,825 cases in the United States. J Clin Oncol. 2008;26(18):3063-72
5. Garcia-Carbonero R, Capdevila J, Crespo-Herrero G, Díaz-Pérez JA, Martínez del Prado MP, Alonso Orduña $\mathrm{V}$, et al. Incidence, patterns of care and prognostic factors for outcome of gastroenteropancreatic neuroendocrine tumors (GEP-NETs): results from the National Cancer Registry of Spain (RGET NE). Ann Oncol. 2010;21(9):1794-803.

6. Lombard-Bohas C, Mitry E, O'Toole D, Louvet C, Pillon D, Cadiot G, et al. Thirteen-month registration of patients with Gastroenteropancreatic endocrine Tumours in France. Neuroendocrinology. 2009;89(2):217-22.

7. Wiedenmann B, Franke WW, Kuhn C, Moll R, Gould VE. Synaptophysin: a marker protein for neuroendocrine cells and neoplasms. Proc Natl Acad Sci U S A. 1986:83(10):3500-4.

8. Eriksson B, Oberg K, Stridsberg M. Tumor markers in neuroendocrine tumors. Digestion. 2000;62(Suppl 1):33-8.

9. Blaschko H, Comline RS, Schneider FH, Silver M, Smith AD. Secretion of a chromaffin granule protein, chromogranin, from the adrenal gland after splanchnic stimulation. Nature. 1967;215(5096):58-9.

10. Modlin IM, Gustafsson BI, Moss SF, Pavel M, Tsolakis AV, Kidd M. Chromogranin A--biological function and clinical utility in neuro endocrine tumor disease. Ann Surg Oncol. 2010;17(9):2427-43.

11. Thiel G, Synapsin I. synapsin II, and synaptophysin: marker proteins of synaptic vesicles. Brain Pathology (Zurich, Switzerland). 1993;3(1):87-95.

12. Nagtegaal ID, Odze RD, Klimstra $D$, Paradis $V$, Rugge $M$, Schirmacher $P$, et al. The 2019 WHO classification of tumours of the digestive system. Histopathology. 2019;76(2):182-8.

13. Uccella S, La Rosa S, Volante M, Papotti M. Immunohistochemical biomarkers of gastrointestinal, pancreatic, pulmonary, and Thymic neuroendocrine neoplasms. Endocr Pathol. 2018;29(2):150-68.

14. Amin MB, SE, Greene FL, et al. AJCC Cancer Staging Manual. 8th ed. New York: Springer; 2017. IBSN978-3-319-40617-6.

15. Ishida M, Sekine S, Fukagawa T, Ohashi M, Morita S, Taniguchi H, et al. Neuroendocrine carcinoma of the stomach: morphologic and immunohistochemical characteristics and prognosis. Am J Surg Pathol. 2013;37(7):949-59.

16. Rindi G, Klöppel G, Alhman H, Caplin M, Couvelard A, de Herder WW, et al. TNM staging of foregut (neuro)endocrine tumors: a consensus proposal including a grading system. Virchows Arch. 2006:449(4):395-401.

17. Song L, Zhai X, Yu S, Ma Y, Wang F, Yu X, et al. Clinical analysis of 547 patients with neuroendocrine tumors in a Chinese population: a singlecenter study. Cancer Med. 2019;8(8):3729-37.

18. Zeng Y-J, Liu L, Wu H, Lai W, Cao J-Z, Xu H-Y, et al. Clinicopathological features and prognosis of Gastroenteropancreatic neuroendocrine tumors: analysis from a single-institution. Asian Pac J Cancer Prev. 2013;14(10):577581.

19. Modlin IM, Oberg K, Chung DC, Jensen RT, de Herder WW, Thakker RV, et al. Gastroenteropancreatic neuroendocrine tumours. Lancet Oncol. 2008;9(1): $61-72$.

20. Kaltsas GA, Besser GM, Grossman AB. The diagnosis and medical Management of Advanced Neuroendocrine Tumors. Endocr Rev. 2004;25(3): 458-511.

21. Bellizzi AM. Immunohistochemistry in the diagnosis and classification of neuroendocrine neoplasms: what can Brown do for you? Hum Pathol. 2020; 96:8-33.

22. Modlin IM, Moss SF, Oberg K, Padbury R, Hicks RJ, Gustafsson Bl, et al. Gastrointestinal neuroendocrine (carcinoid) tumours: current diagnosis and management. Med J Aust. 2010;193(1):46-52.

23. Campana D, Nori F, Piscitelli L, Morselli-Labate AM, Pezzilli $R$, Corinaldesi $R$, et al. Chromogranin a: is it a useful marker of neuroendocrine tumors? J Clin Oncol. 2007;25(15):1967-73.

24. Miller HC, Drymousis P, Flora R, Goldin R, Spalding D, Frilling A. Role of Ki-67 proliferation index in the assessment of patients with neuroendocrine Neoplasias regarding the stage of disease. World J Surg. 2014;38(6):1353-61.

25. Janson ET, Holmberg L, Stridsberg M, Eriksson B, Theodorsson E, Wilander E, et al. Carcinoid tumors: analysis of prognostic factors and survival in 301 patients from a referral center. Ann Oncol. 1997:8(7):685-90.

26. Sugimoto S, Hotta K, Shimoda T, Imai K, Yamaguchi Y, Nakajima T, et al. The Ki-67 labeling index and lymphatic/venous permeation predict the metastatic potential of rectal neuroendocrine tumors. Surg Endosc. 2016; 30(10):4239-48.

27. Hamilton NA, Liu T-C, Cavatiao A, Mawad K, Chen L, Strasberg SS, et al. Ki-67 predicts disease recurrence and poor prognosis in pancreatic neuroendocrine neoplasms. Surgery. 2012;152(1):107-13. 
28. Tian T, Gao J, Li N, Li Y, Lu M, Li Z, et al. Circulating Chromogranin a as a marker for monitoring clinical response in advanced Gastroenteropancreatic neuroendocrine tumors. PLoS One. 2016;11(5):e0154679.

29. Genc CG, Falconi M, Partelli S, Muffatti F, van Eeden S, Doglioni C, et al. Recurrence of pancreatic neuroendocrine tumors and survival predicted by Ki67. Ann Surg Oncol. 2018;25(8):2467-74.

30. Arnold R, Wilke A, Rinke A, Mayer C, Kann PH, Klose KJ, et al. Plasma chromogranin a as marker for survival in patients with metastatic endocrine gastroenteropancreatic tumors. Clin Gastroenterol Hepatol. 2008;6(7):820-7.

31. Lindholm EB, Lyons J 3rd, Anthony CT, Boudreaux JP, Wang YZ, Woltering

EA. Do primary neuroendocrine tumors and metastasis have the same characteristics? J Surg Res. 2012;174(2):200-6.

32. Singh S, Hallet J, Rowsell C, Law CH. Variability of Ki67 labeling index in multiple neuroendocrine tumors specimens over the course of the disease. Eur J Surg Oncol. 2014;40(11):1517-22.

33. Grillo F, Albertelli M, Brisigotti MP, Borra T, Boschetti M, Fiocca R, et al. Grade increases in Gastroenteropancreatic neuroendocrine tumor metastases compared to the primary tumor. Neuroendocrinology. 2016;103(5):452-9.

34. Keck KJ, Choi A, Maxwell JE, Li G, O'Dorisio TM, Breheny P, et al. Increased grade in neuroendocrine tumor metastases negatively impacts survival. Ann Surg Oncol. 2017;24(8):2206-12.

35. Shi H, Zhang Q, Han C, Zhen D, Lin R. Variability of the Ki-67 proliferation index in gastroenteropancreatic neuroendocrine neoplasms - a singlecenter retrospective study. BMC Endocr Disord. 2018;18(1):51.

36. Shi C, Gonzalez RS, Zhao Z, Koyama T, Cornish TC, Hande KR, et al. Liver metastases of small intestine neuroendocrine tumors: Ki-67 heterogeneity and World Health Organization grade discordance with primary tumors. Am J Clin Pathol. 2015;143(3):398-404.

37. Cives M, Soares HP, Strosberg J. Will clinical heterogeneity of neuroendocrine tumors impact their management in the future? Lessons from recent trials. Curr Opin Oncol. 2016;28(4):359-66.

\section{Publisher's Note}

Springer Nature remains neutral with regard to jurisdictional claims in published maps and institutional affiliations.

Ready to submit your research? Choose BMC and benefit from:

- fast, convenient online submission

- thorough peer review by experienced researchers in your field

- rapid publication on acceptance

- support for research data, including large and complex data types

- gold Open Access which fosters wider collaboration and increased citations

- maximum visibility for your research: over $100 \mathrm{M}$ website views per year

At $\mathrm{BMC}$, research is always in progress.

Learn more biomedcentral.com/submissions 